This item was submitted to Loughborough's Research Repository by the author.

Items in Figshare are protected by copyright, with all rights reserved, unless otherwise indicated.

\title{
Relative behaviour of premature failures in adhesively plated RC beam using controllable and existing parameters
}

PLEASE CITE THE PUBLISHED VERSION

https://doi.org/10.1016/j.compstruct.2017.08.006

\section{PUBLISHER}

(C) Elsevier

VERSION

AM (Accepted Manuscript)

\section{PUBLISHER STATEMENT}

This work is made available according to the conditions of the Creative Commons Attribution-NonCommercialNoDerivatives 4.0 International (CC BY-NC-ND 4.0) licence. Full details of this licence are available at: https://creativecommons.org/licenses/by-nc-nd/4.0/

\section{LICENCE}

CC BY-NC-ND 4.0

\section{REPOSITORY RECORD}

Khan, Mohammad Arsalan, Jamal El-Rimawi, and Vadim V. Silberschmidt. 2019. "Relative Behaviour of Premature Failures in Adhesively Plated RC Beam Using Controllable and Existing Parameters". figshare. https://hdl.handle.net/2134/26450. 


\title{
Relative behaviour of premature failures in adhesively plated RC beam using controllable and existing parameters
}

\author{
Mohammad Arsalan Khan ${ }^{\text {a, } * \text {, Jamal El-Rimawi }}{ }^{\text {, }}$, Vadim V. Silberschmidt ${ }^{\text {b }}$ \\ a School of Civil and Building Engineering, Loughborough University, Leicestershire, Loughborough \\ LE11 3TU, United Kingdom \\ b School of Mechanical and Manufacturing Engineering, Loughborough University, Leicestershire, \\ Loughborough LE11 3TU, United Kingdom
}

\begin{abstract}
Retrofitting of RC beam by gluing a steel plate at the soffit has been a widely adopted technique due to its ease of use, calculations and having minimal variations on structural aesthetics; hence, a large number of such retrofitted structures exist today. However, such structures have also failed frequently due to the formation of premature failures such as peeling and debonding. The further investigations conducted in literature indicated that such undesirable failures can be effected by a large number of geometrical and material parameters. Although, the characterisation and relative influence of such parameters on modes of failures remain unknown; as the past studies have been largely case sensitive or focussing on a small set of parameters. Therefore, to address these issues, a simple but focussed numerical model has been validated through literature for multiple modes of failures over wide range of possible parameters. Further, targeting the response of beam and its critical locations, the authors of this study suggest that the understanding of relative impact of effective parameters, in terms of beam capacity and brittleness of modes of failure, can be broadly utilised to re-evaluate the cause(s) of failure(s) through case studies, or to predict the future of retrofitted structures/beams.
\end{abstract}

\section{Introduction}

Plating method(s) has been widely adopted for strengthening of RC beams due to economic and aesthetic reasons [1-6]. Generally, it is considered that adhesively plated beams fail prematurely in debonding or peeling before reaching its desired capacity. While in this study it is noticed that such beams largely fail in debonding or peeling or both even after achieving its desired capacity in yielding; that is, this uncertainty may depend on beam parameters that vary from one study to another. In addition, such parameters may have different level of influence on different failure types; for example debonding is different than peeling in a way that former is caused due to the formation of interfacial cracks at a adhesiveconcrete interface, while latter is a consequence of formation and propagation of flexural crack at plate end [7]. Therefore, other non-critical cracks can propagate into a critical mode of failure. Focusing on root causes of cracks, the objectives of this paper is to characterise and associate geometrical and material parameters with the formation of cracks in terms of location of formation and/

\footnotetext{
* Corresponding author at: Department of Civil Engineering, Z. H. College of Engineering and Technology, Aligarh Muslim University, Aligarh 202002, Uttar Pradesh, India.

E-mail address: mohd.arsalan.khan@hotmail.co.uk (M.A. Khan).
}

or propagation and final cause of ultimate mode of failure (catastrophic or gradual).

\subsection{Description of crack modes}

Premature brittle failures of undesirable nature that are unique to plated beam consist of interface failure at mid-span and plateend (debonding), cover rip-off at plate end (peeling); and desired mode of ductile failures, that is yielding of steel - external, internal or both. The other modes of non-premature and brittle failures include crushing of concrete in compression, and shear failure. Investigating the cracks' formation through relevant literature [8], it can be observed that, depending upon the location of a flexural crack, the propagation of flexural crack may develop into an interfacial crack (if flexural crack lies along the plate) or peeling (if flexural crack lies at plate-end). Sebastian [9] pointed out that debonding at mid-span region is a self-propagating process. A peeling failure can be easily visualised but not easy to quantify [10]. Therefore, debonding and peeling failures are of critical importance due to their catastrophic nature of propagation, along with the nature of contributing factors/parameters.

For instance, favourable geometrical properties that assist to further the propagation of debonding crack at mid-span are large shear span, long plate with high width-to-thickness ratio similar 
to beam URB2 [11]; those assisting the debonding at shear span are plate with low width-to-thickness ratio as identified by Teng et al. [12].

Plates curtailed at regions of high flexural stress (that is, further from support) favour peeling and debonding at plate-end $[13,14]$; however, it is unclear whether beam will fail due to either debonding or peeling. Therefore, in this relation, the author suggests to also identify and characterise the importance/role of material parameters (if any).

\subsection{Parameters}

The characterisation of failure modes based on primary (controllable), secondary (existing) and local (boundary conditions) parameters are discussed next.

\subsubsection{Primary or controllable parameters}

Primary parameters are geometrical and/or material parameters influencing mode(s) of failure that can be controlled directly before a section can be retrofitted with a plate, such as the properties of the adhesive and that of the plate. The geometrical parameters are the adhesive thickness, plate thickness, plate width to thickness ratio and plate length; while the material parameters are adhesive stiffness and the strength of the concrete-adhesive interface. This category of parameters are of direct interest to an engineer during retrofitting over existing parameters.

\subsubsection{Secondary or existing parameters}

These are existing parameters, such as the cross-section dimensions and rebars, which already exist and cannot be changed prior to retrofitting the beam. However, it is still important to study their effect on beam as they can be indirectly related to a combination of primary parameters as far as stress distribution and modes of failures are concerned. An engineer could be working on a beam having a specific set of existing parameters. For instance, two beams of same dimensions can behave completely differently for a different set of existing parameters. For example, strength and fracture energy of material in tension (such as concrete) may have a noticeable influence on the load of initiation of flexural crack; for example [15]. Due to lack of detailed literature, these topics are also covered in present study.

In addition, there are parameters that have little or no influence on premature failures; for example, variation of compressive strength of concrete [16-18].

\subsubsection{Local parameters}

Such parameters are rather related with the local or boundary conditions of the beam such as shear-span to depth ratio. Altering shear-span to sectional-depth ratio results into change in the behaviour of beam, particularly in terms of mode of failure in plated beam.

\section{Material and method}

Coronado [19] specifically dealt with peeling mode of failure for FRP plated RC sections using a Damage Band approach (smeared cracking) embedded in ABAQUS. However, the drawback of Damage Band approach is that it is complex and case sensitive to load-displacement behaviour. Therefore, unlike the works of Jumaat and Alam [20], Adhikary and Mutsuyoshi [21], Arslan et al. [22], Oh et al. [23] and Ziraba and Baluch [17], cohesive element foundations are used through a novel approach to capture the effect of material properties of adhesive on cracks and to differentiate between plate-end debonding and peeling. The debonding along the concrete-adhesive-plate interface is captured by cohesive zone element for bi-linear material behaviour as shown in Fig. 1. It shows that a debonding crack can now also be arrested at plate end in addition to peeling as a consequence of propagation of flexural crack in either (or both) direction(s) (upwards for peeling or/and along the interface for debonding). Fig. 1(b) indicates a mixed-mode behaviour of the interface along the shear span, and that can be captured by the use of traction-separation law in both directions (normal and transverse).

The choice of Concrete Damaged Plasticity model for concrete and the Cohesive Zone Model (CZM) for adhesive are capable to retain damage to indicate closeness to real conditions. In addition, unlike Smeared Crack model, Concrete Damaged Plasticity model assumes the retention of permanent plastic strain (not total strain values) after damage initiation (both in tension and compression concrete).

\subsection{Numerical model}

FE Modeling of nonlinear static problem is done through a commercially available software ABAQUS [24] (using a 2D plane stress approach), utilising a Full-Newton solving method. A meshed model of the beam with boundary conditions and a y-axis symmetry is represented in [25]. Model is a combination of discrete (for adhesive) and continuum (for concrete and steel) elements. Having unity base width, the 4-noded cohesive elements (COH2D4) are
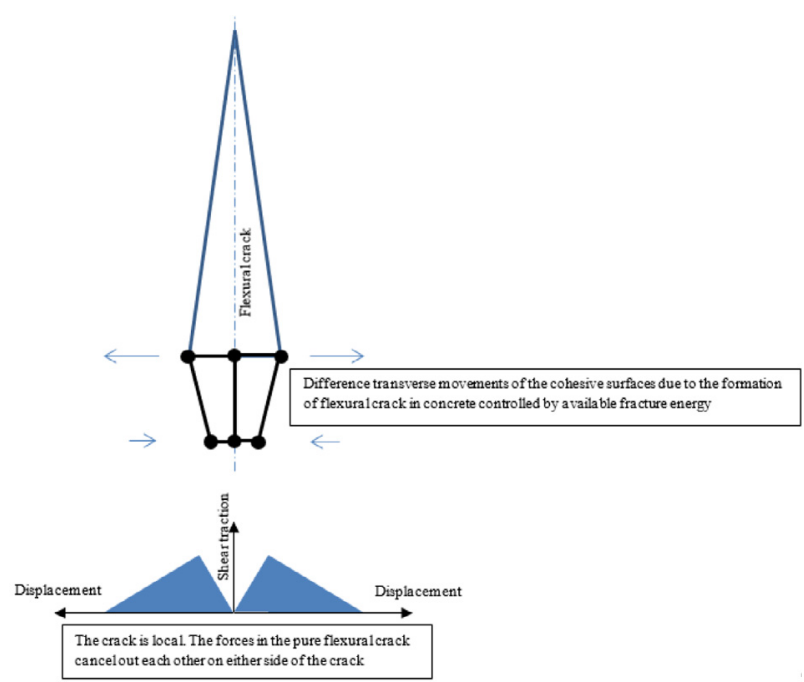

(a)

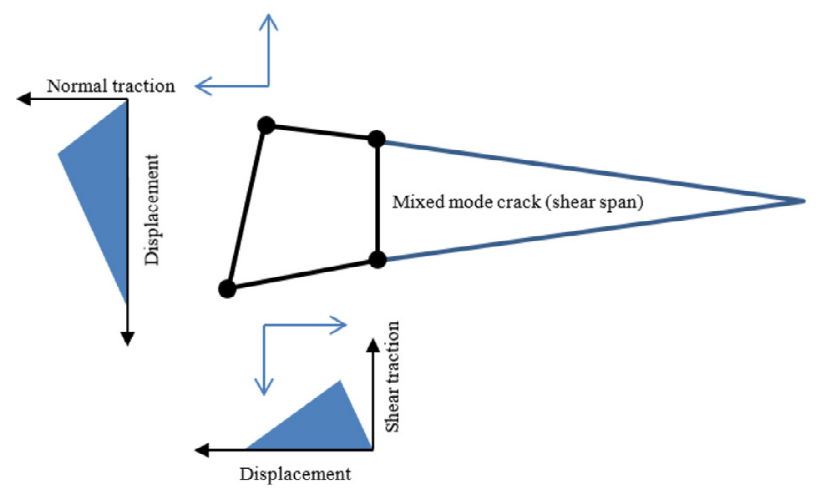

(b)

Fig. 1. Graphical representation of behaviour cohesive element: (a) at mid-span due to the formation of flexural crack, (b) at plate-end under mixed-mode condition of stresses. 
staked between concrete and steel surfaces along the length of the beam; while a quadratic quadrilateral 2D continuum element with reduced integration (CPS8R) is used elsewhere.

\subsection{Materials and parameters}

\subsubsection{Fracture energy of tensile concrete $\boldsymbol{G}_{\boldsymbol{f c}}$}

Variations have been found in literature considering the values for $G_{f c}$ for plain and reinforced concrete beams (that is, reinforcement as rebars in tension). A range of $0.090-0.176 \mathrm{~N} / \mathrm{mm}$ has been specified by Azad et al. [26]. Based on literature, ABAQUS documentation indicates $G_{f c p}$ (for plain concrete) to lie within the range of $0.04-0.12 \mathrm{~N} / \mathrm{mm}$ respectively for typical construction concrete (with a compressive strength of approximately $20 \mathrm{MPa}$ ) and high-strength concrete (with a compressive strength of approximately $40 \mathrm{MPa}$ ). Wittmann [27] showed that fracture energy and strain softening depend on the mechanical interaction of aggregates with the cement based matrix. He summarised the range of $G_{f c p}$ for hardened cement paste (maximum aggregate size as $0.01 \mathrm{~mm}$ ) as $0.0095-0.05 \mathrm{~N} / \mathrm{mm}$, for normal concrete (maximum aggregate size as $50 \mathrm{~mm}$ ) as $0.1-0.6 \mathrm{~N} / \mathrm{mm}$ and for dam concrete (maximum aggregate size as $120 \mathrm{~mm}$ ) as $0.2-0.7 \mathrm{~N} / \mathrm{mm}$. In his plots for cylinder splitting load verses crack opening for varied strengths of concrete, although, there was an overall increase in $G_{f c p}$ for higher strength concretes, the strengths were ultimately converging to an almost common value of crack opening. This indicated that there is hardly a specific relationship between the crack opening and elastic displacement.

Whereas, for reinforced concrete beams, BS8110 [28] assumes the softening strain to be $30 \varepsilon$ (i.e. 30 times elastic strain $\varepsilon$ ). Azad et al. [26] have shown that the value of $G_{f c r}$ (for reinforced concrete) depends on the location of tensile rebars, area of tension steel and with the development of crack. For example, for beam B8, a comparatively lower value of around $0.1 \mathrm{~N} / \mathrm{mm} G_{f c r}$ was noted closer to rebar than the maximum value of $1.49 \mathrm{~N} / \mathrm{mm}$ obtained with further extension of crack (hyperbolic curve). This has to be reflected in the current FE model, with $G_{f c r}$ above rebar layer is assumed to be $1 \mathrm{~N} / \mathrm{mm}$.

It is noteworthy that, covercrete lies in a region which may or may not be reinforced by external plate. For $G_{f c}$, a range of $0.03-$ $1 \mathrm{~N} / \mathrm{mm}$ has been considered for parametric study to cover a practical limit for static loading. We consider the values for $G_{f c}$ as: 0.03 (equivalent to $21 \varepsilon$ ), 0.1 (equivalent to $71 \varepsilon$ ), 0.3 (equivalent to $214 \varepsilon$ ), and $1 \mathrm{~N} / \mathrm{mm}$ (equivalent to $714 \varepsilon$ ). The strain $\varepsilon$ at failure strength of 2.87 MPa is 0.0001 , at which a flexural crack(s) starts to appear. The control value (calibrated) for the section (S41) tested by Oh (Oh et al., 2003a) is taken as $0.042 \mathrm{~N} / \mathrm{mm}$ (equivalent to $30 \varepsilon$ ).

\subsubsection{Thickness of adhesive layer $\boldsymbol{t}_{\boldsymbol{g}}$}

Oh [23] presented tests aimed at exploring the local failure behaviour of strengthened plated beams under double lap pullout tests and half-beam tests (i.e. unidirectional loading). The adhesive thickness directly influenced the failure load of the members. The tests also showed an increase in the average shear strength at the interface as the thickness of the adhesive is increased.

On another study, [29] tested full size beams. Unlike [30], Oh $[23,29]$ reported that the ultimate capacity of a strengthened beam increased slightly with the increase of the adhesive thickness. [29] noted that this may be caused by the late initiation of plate separation. [30] have shown that using thicker adhesive may lead to: flexural failure, increase in the flexural strengths and stiffness of the beams. However, they did not mention the percentage change in overall elongation, of adhesive used, with change in thickness such as indicated by Jones et al. [31] and Sika [32]. Therefore, in present FE model, this is achieved by fixing the value for constitutive thickness of cohesive zone (taken as unity) while the geometrical thickness is varied.

Largely, four thicknesses for adhesive have been used by researchers, which are $1 \mathrm{~mm}, 3 \mathrm{~mm}, 5 \mathrm{~mm}$ and $7 \mathrm{~mm}$. Our numerical specimens will correspond to the respective sections of 541 , S43, S45 and S47 from [29].

\subsubsection{Tensile strength for concrete $\boldsymbol{f}_{t c}$}

In real scenario the nature of problem corresponds to the static loading, while the test data available for validation is largely laboratory tests that may have slightly higher rate of loading. Tensile strength increases with the increase in strain rate [33]; for high strain rates (spall experiments for dynamic analysis), they noticed an increase in $f_{\text {tc }}$ up to around $55 \%$ of compressive strength. For $f_{t c}$ static testing, $f_{\text {tc }}$ is recorded to be around $7 \% f_{c}^{\prime}$ in NCL technical report [34]. For design purposes, BS8110 [28] considers value of $f_{t c}$ to be $10 \% f_{c u}$ and $\mathrm{ACI}[35]$ as $0.33 \sqrt{f_{c}^{\prime}}$.

Therefore, the tensile strength has been varied at 7\% (2 MPa), $10 \%$ (28.7 MPa, control value), 25\% (7.18 MPa) and 50\% (14.35 MPa) of cylindrical compressive strength for a control beam. The corresponding elastic strains are 0.00007, 0.0001 (control), 0.00024 , and 0.00048; at these strains the flexural crack would appear. The plastic (at complete failure) to elastic strain ratios are $60 \varepsilon, 30 \varepsilon$ (control), $5 \varepsilon$, and $1.2 \varepsilon$ respectively; the last two values are lower than the one recommended by ABAQUS of $10 \varepsilon$ for fairly heavily reinforced concrete.

\subsubsection{Plate width to thickness ratio $\boldsymbol{b}_{\boldsymbol{p}} / \boldsymbol{t}_{\boldsymbol{p}}$}

A value of $b_{p} / t_{p}<40$ leads to premature failure(s) at plate end while values greater than 60 would conclude to specimens failing in flexure $[30,31,36]$. However, the specimen of Oh et al. (Oh et al., 2003a) showed plate yielding as first mode of failure at $b_{p} / t_{p}=50$ $(\langle 60)$. In addition, the specimen(s) of [2] prematurely failed at $b_{p} / t_{p}$ of 67 . The cause of such discrepancies in results is not clear, which might have to do with an overall geometrical aspect of plated beam, such as location of load and depth of section. The $b_{p} / t_{p}$ ratio is varied by: changing the cross-sectional area of plate (alters the load capacity of section) and keeping the area constant. Broadly considering the limit 140,60[, which is less than or equal to 40 and more than or equal to 60 , the $b_{p} / t_{p}$ ratio has been varied for plate thicknesses falling within practical range, maintaining the section to be under-reinforced or balanced. Keeping the plate width constant, the plates $\left(b_{p} / t_{p}\right.$ ratio) of $2 \mathrm{~mm}$ (75), $3 \mathrm{~mm}$ (50), $4 \mathrm{~mm}$ (37.5, control) and $5 \mathrm{~mm}$ (30) are used. Maintaining the area constant, the plates $\left(b_{p} / t_{p}\right.$ ratio) of $2 \mathrm{~mm}(150), 4 \mathrm{~mm}$ (37.5, control), $5 \mathrm{~mm}$ (24), $6 \mathrm{~mm}$ (16.7), $7 \mathrm{~mm}$ (12.3) and $8 \mathrm{~mm}$ (9.4) are tested.

\subsubsection{Plate length in shear-span to sectional-depth ratio $\boldsymbol{l}_{\boldsymbol{p s}} / \boldsymbol{D}$}

Theoretically, for a four-point loading problem, the fluctuations in plate length extending outside the pure flexural span would not affect the capacity of the beam in flexure unless rebars remain under their yielding limit outside plate-end(s). Through experiments, Oh et al. [29] emphasised that full-span-length strengthening with steel plate helps in maximising the strengthening effects by delaying the plate separation; Arslan et al. [22] reported debonding failure. Mohamed et al. [37] and Arslan et al. [22] reported that the external plate curtailed within flexural span will fail in peeling. The normal distribution of tensile strains may be affected by the geometrical discontinuities [31]. For a given theoretical flexural theoretical capacity, the effect of varying plate ends is investigated.

Considering half beam, four lengths of the plate have been considered: three outside the pure flexural span (one of which extends close to support) and the one curtailing at the end of pure flexural 
span. In resent case, $D$ is $250 \mathrm{~mm}$, this yields $l_{p s} / D$ ratio of $0,1,2$ and 2.6 for $l_{p s}$ of $0 \mathrm{~mm}, 250 \mathrm{~mm}, 500 \mathrm{~mm}$ and $650 \mathrm{~mm}$ (control beam) respectively.

\subsubsection{Shear span to depth ratio $\boldsymbol{a} / \boldsymbol{d}$}

The $a / d$ ratio has a direct influence on theoretical load capacity [23]; however, such observations are incompatible with the experimental investigations [29]. In addition, they have indicated the impact of this ratio on modes of failures, subjected to minimum value of 4.77 (beyond which is a shear block failure) and a maximum value of 1.36 (beyond which a problem reduces to a 3point loading beam). However, such limits may vary depending on sectional geometry (available shear-span and depth). The $a / d$ ratio is varied at $4.77,4.09,3.18,2.27$ and 1.36. That is, for the effective depth of the beam of $220 \mathrm{~mm}$, the corresponding shear spans are $1050 \mathrm{~mm}, 900 \mathrm{~mm}, 700 \mathrm{~mm}, 500 \mathrm{~mm}$ and $300 \mathrm{~mm}$ respectively.

\section{Results}

\subsection{Validation}

Validations have been conducted through the specimens of Heathcote [38], Jones et al. [11] and Oh et al. [29] to cover wide range of parameters and possible modes of failure.

\subsubsection{Specimens of PM Heathcote [38]}

Heathcote [38] tested a large number of RC beams for secondary parameters: varying thickness of covercrete and varying internal reinforcements, with plates bolted at soffit. He also tested a few plated beams without bolts; of which, two beams P1 and P3A are modeled for validations. Span/Shear-span are 2000/850 mm, width/height are $150 / 300 \mathrm{~mm}$. The position of tension rebars (2 numbers of $10 \mathrm{~mm}$ dia.) varied with $\mathrm{P} 1$ having a cover thickness of $25 \mathrm{~mm}$ and P3A with $50 \mathrm{~mm}$. He adopted an adhesive through a commercial supplier Sika (Sikadur, 2012). The plate has a length/width/thickness of 1700/150/5 mm.

The validation studies for load-deflection behaviour (see Fig. 2 (a)), distribution of longitudinal strains along the plate length for beam P1 (see Fig. 2(b)) and for beam P3A (see Fig. 2(c)) are shown next.

Both FE sections failed in peeling as the same mode of failure reported by [38]; the first failure cracks appeared at $77 \mathrm{kN}$ for P1 and $72.5 \mathrm{kN}$ for P3A compared to experimental values of $78.9 \mathrm{kN}$ for P1 and $75.3 \mathrm{kN}$ for P3A. Therefore, the decrease in load of appearance of flexural crack at plate end is a result of increased depth of clear cover. This observation can be directly related with the available fracture energy due to the position of rebars [26].

\subsubsection{Specimen of Jones et al. [11]}

The modes of failure matched with the literature along with the overall behaviour; the experimental and numerical loads at ultimate capacities and at first failure, for the beams URB1, URB2 URB4 and URB5, are summarised in Table 1.

In addition, the plots in Fig. 3 confirms the parametric influence of varying plate thickness, that is, the increasing plate thickness results in increased failure load of the beam to some extent and then decreases as the mode of failure is changed from flexural failure (for overall under-reinforced beams) to premature failure (for balanced to over-reinforced beams). Thicker plate also increases the stiffness of the beam, thereby comparably leading to smaller deflections at lower values of loads.

The distribution of longitudinal strains along the adhesivecovercrete interface are validated; this is further utilised to validate the average crack spacing $s_{a v g}$.

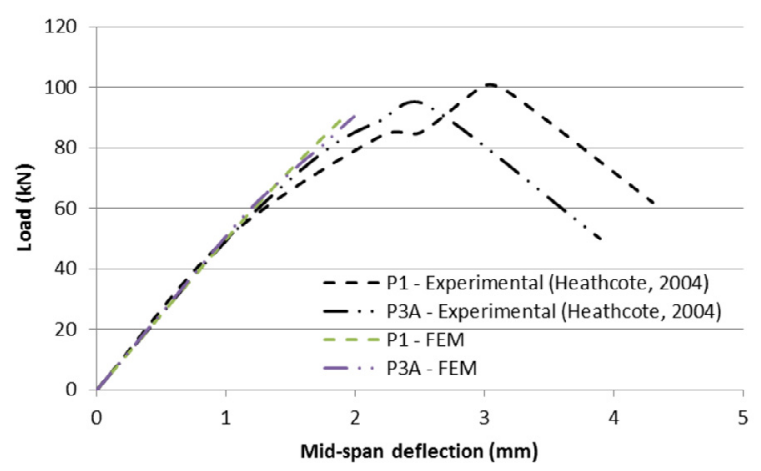

(a) Load verses mid-span deflection

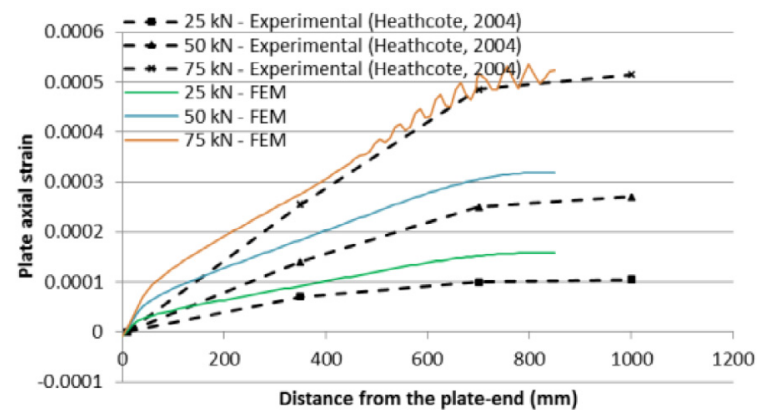

(b) Longitudinal strain distribution along the plate for beam P1

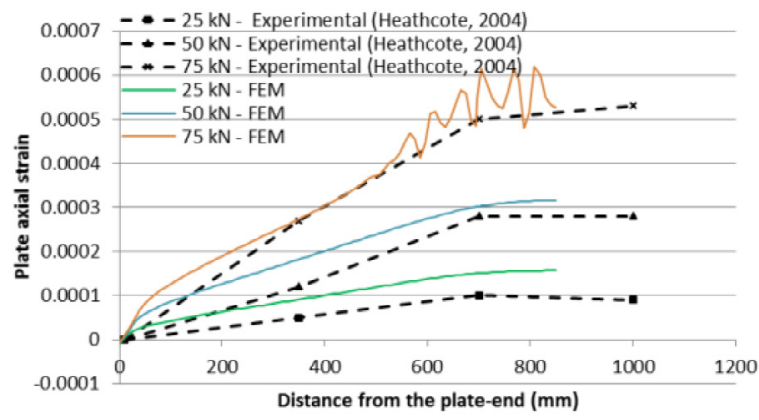

(c) Longitudinal strain distribution along the plate for beam P3A

Fig. 2. Beams $\mathrm{P} 1$ and $\mathrm{P} 3 \mathrm{~A}$.

$s_{\text {avg }}=\frac{1}{(n-1)} \sum_{i>0}^{n-1} s_{i}$

Where $s_{i}$ indicates spacing between two consecutive complete cracks (see Fig. 4); for a maximum of $n$ number of cracks. The theoretical value of flexural strain at complete crack demonstrates that the element has fully failed to transfer any further stresses across its boundaries. The spacing between crack tips are identified and encircled in red.

The validated results are summed up in Table 1.

Meanwhile, the crack spacing, crack height and number of crack can be directly validated using the visualisation mode in ABAQUS by adjusting the minimum starting strains as required. These are further verified theoretically using Appendix. For example, fracture energy of concrete $G_{f c}$ is calculated for single crack over elemental characteristic length $b$ using Eq. (11) (see Appendix) with width of complete crack $\delta^{f}$ of 0.0059 equal to the calibrated equivalent stain of $20 \epsilon$, where $\varepsilon$ is maximum elastic strain in tension. The value of $G_{f c}$, for tensile strength of concrete $f_{t}$ of $5.072 \mathrm{MPa}$, strain of 0.00028 for aggregate of $20 \mathrm{~mm}$ and $b$ of $10 \mathrm{~mm}$, is evaluated to be $0.142 \mathrm{MPa}-\mathrm{mm}$. 
Table 1

Comparison of behaviour of cracks and load capacities.

\begin{tabular}{|c|c|c|c|c|c|c|c|c|c|c|}
\hline Beam & $\begin{array}{l}\text { Load at First crack } \\
(\mathrm{kN}): \text { Exp./FEM } \\
\text { (crack type: } \\
\text { Flexural) }\end{array}$ & $\begin{array}{l}\text { Crack spacing } \\
(\mathrm{mm}) \text { at } 25 \mathrm{kN} \text { : } \\
\text { Exp./FEM (crack } \\
\text { type: Flexural) }\end{array}$ & $\begin{array}{l}\text { Crack height } \\
\text { (mm) at } 25 \mathrm{kN} \text { : } \\
\text { Exp./FEM (crack } \\
\text { type: Flexural) }\end{array}$ & $\begin{array}{l}\text { Crack width (mm) } \\
\text { at maximum } \\
\text { capacity: Exp./ } \\
\text { Theoretical }\end{array}$ & $\begin{array}{l}\text { Crack height (mm) } \\
\text { at maximum } \\
\text { capacity: Exp./ } \\
\text { FEM/Theoretical }\end{array}$ & $\begin{array}{l}\text { Failure type } \\
\text { sequence: } \\
\text { Exp./FEM }\end{array}$ & $\begin{array}{l}\text { Load of } \\
\text { appearance } \\
\text { of first failure } \\
\text { crack } \\
\text { (kN): Exp./FEM }\end{array}$ & $\begin{array}{l}\text { Depth of } \\
\text { Neutral } \\
\text { Axis (mm) Exp./ } \\
\text { FEM/ } \\
\text { Theoretical }\end{array}$ & $\begin{array}{l}\text { Maximum Load } \\
(\mathrm{kN}) \text { Exp./FEM/ } \\
\text { Theoretical }\end{array}$ & $\begin{array}{l}\text { Failure } \\
\text { Moment } \\
(\mathrm{kNm}) \\
\text { Exp./ } \\
\text { Theoretical }\end{array}$ \\
\hline URB1 [11] & $7.5 / 6$ & $63 / 51$ & $101 / 75$ & $0.25 / 0.14$ & $110 / 101 / 104$ & Flexural/Flexural & & $40 / 49 / 43.4$ & $28.1 / 27.8 / 41.2$ & $10.54 / 15.4$ \\
\hline URB2 [11] & $8.5 / 8.5$ & $65 / 45$ & $84 / 65$ & $0.21 / 0.12$ & $108 / 86 / 102$ & $\begin{array}{l}\text { PY, PS mid/PY, PS } \\
\text { mid }\end{array}$ & $-/ 13$ & $-/ 64 / 48.5$ & $40 / 35.9 / 46.8$ & $15 / 17.5$ \\
\hline URB4 [11] & $10 / 13$ & $\begin{array}{l}\text { 69/uniformly } \\
\text { distributed }\end{array}$ & $65 / 55$ & $0.06 / 0.08$ & $84 / 70 / 88.1$ & PS, PY/PS, PY & 55.9/more than 50 & $70 / 80 / 61.8$ & $57.5 / 49.7 / 61.2$ & $21.56 / 22.9$ \\
\hline URB5 [11] & -Not clear-/15 & $\begin{array}{l}\text { 89/uniformly } \\
\text { distributed }\end{array}$ & $68 / 44$ & $0.04 / 0.04$ & $83 / 45 / 62.1$ & $\mathrm{PS} / \mathrm{PS}$ & $49.6 /$ more than 42 & $-/ 105 / 86.6$ & $53.1 / 41.2 / 86.4$ & $19.91 / 32.4$ \\
\hline Unplated [29] & & & & $-/ 0.06$ & $-/ 166 / 182$ & Flexural/Flexural & (See Table 2) & $65 / 84 / 64.8$ & $89 / 79.3 / 96$ & $31.2 / 33.6$ \\
\hline S23 [29] & & & & $-/ 0.03$ & $-/ 160 / 157$ & PY, PS, DT/PY, PS, DT & & 91.5/90/91.4 & 136/144.3/135 & $47.6 / 47.4$ \\
\hline S33 [29] & & & & $-/ 0.03$ & $-/ 135 / 143$ & PY, PS, DT/PY, PS, DT & & $97 / 115 / 104.7$ & $137 / 137.5 / 156$ & $48 / 54.6$ \\
\hline S43 [29] & & & & $-/ 0.02$ & $-/ 126 / 129$ & PS, DT/PS, DT, PY & & $118 / 124 / 117.9$ & $126 / 132.4 / 175$ & $44.1 / 61.4$ \\
\hline S53 [29] & & & & $-/ 0.02$ & $-/ 120 / 117$ & PS, DT/PS, DT & & $-/ 130 / 129.1$ & $142 / 129 / 192$ & $49.7 / 67.2$ \\
\hline S41 [29] & & & & $-/ 0.02$ & $-/ 128 / 127$ & PS, DT/PS, DT & & $117 / 122 / 117.8$ & $125 / 134.3 / 174$ & $43.8 / 61$ \\
\hline S45 [29] & & & & $-/ 0.02$ & $-/ 127 / 131$ & PS, DT/-, DT & & $111 / 123 / 117.9$ & $134 / 132.5 / 177$ & $46.9 / 61.8$ \\
\hline S47 [29] & & & & $-/ 0.02$ & $-/ 126 / 133$ & PS, DT/-, DT & & $118 / 124 / 118$ & $150 / 131.8 / 178$ & $52.5 / 62.2$ \\
\hline S43S1 [29] & & & & $-/ 0.02$ & $-/ 167 / 133$ & PY, PS, DT/PY, PS, DT & & $-/ 83 / 118$ & $132 / 132.9 / 117$ & $69.3 / 62.2$ \\
\hline S43S2 [29] & & & & $-/ 0.02$ & $-/ 135 / 129$ & PS, DT/PS, PY, DT & & $-/ 115 / 117.9$ & $128 / 132.6 / 136$ & $57.6 / 61.4$ \\
\hline S43S3 [29] & & & & $-/ 0.02$ & $-/ 127 / 129$ & PS, DT/PS, DT & & $-/ 123 / 117.9$ & $135 / 132.9 / 246$ & $33.8 / 61.4$ \\
\hline S43S4 [29] & & & & $-/ 0.02$ & $-/ 125 / 129$ & SC, PS/-, PS & & $-/ 125 / 117.9$ & $221 / 140.4 / 409$ & $33.2 / 61.4$ \\
\hline P1 [38] & $61.9 / 45$ & & & $-/ 0.11$ & $-/ 135 / 196$ & $\mathrm{DT} / \mathrm{DT}$ & 78.9/77 & $-/ 165 / 100$ & $100.6 / 90.7 / 259$ & $-/ 110$ \\
\hline P3A [38] & 40 to $50 / 41$ & & & $-/ 0.11$ & $-/ 140 / 200$ & DT/DT & $75.3 / 72.5$ & $-/ 160 / 96.6$ & $94.2 / 90.3 / 251$ & $-/ 107$ \\
\hline
\end{tabular}

PY = plate yielding, PS = plate separation/debonding at plate end, PS mid = Debonding at plate mid, DT = diagonal tension failure/peeling, SC = shear compression failure 


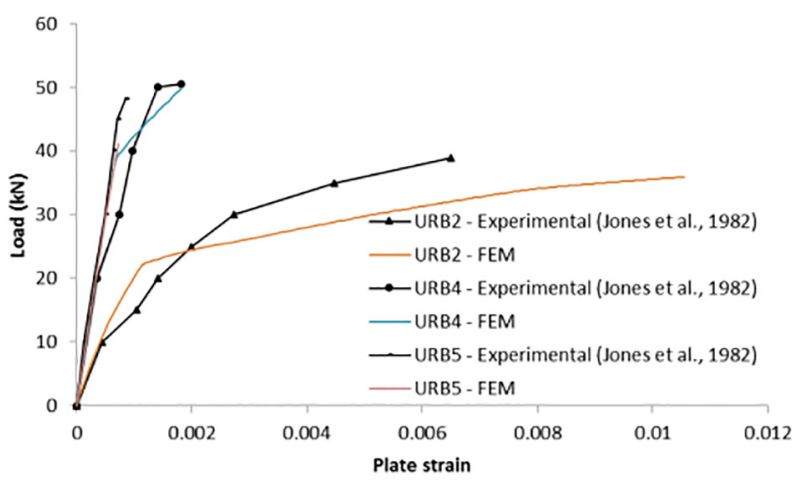

Fig. 3. Load verses longitudinal strain for plate at mid-span.

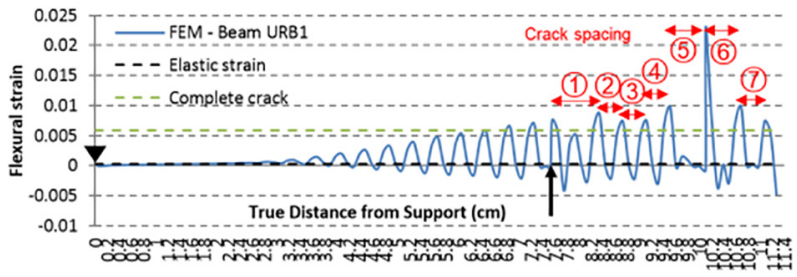

Fig. 4. Flexural strain distribution at $25 \mathrm{kN}$ for beam URB1.

The average crack width $\delta$ is simply calculated using Eq. (2), this is equal to the plastic strain at bottom fibre times the elemental characteristic length $b$. At capacity of beam section, the strain at bottom fibre is noted at 0.01376 minus the elastic strain for concrete of 0.00028 . With $b$ of $10 \mathrm{~mm}, \delta$ is evaluated as $0.1348 \mathrm{~mm}$.

Since here $\delta>\delta^{f}$, Case III applies (see Appendix), that is, complete crack forms, therefore, $G_{f c}^{\text {gross }}$ is evaluated using Eq. (12) as 3.42 MPa-mm and $G_{f c}^{\text {notch }}$ using Eq. (15) as $3.28 \mathrm{MPa}-\mathrm{mm}$.

The average height of crack can be calculated at $\delta$ using Eq. (3) as $104 \mathrm{~mm}$. For comparison, the crack height given by Jones et al. (Jones et al., 1982) is $110 \mathrm{~mm}$ and FE model is $101 \mathrm{~mm}$ (see Table 1 ). And the average height of notch or complete-crack $d \prime$ is calculated using Eq. (4) as $61 \mathrm{~mm}$ (since $\Delta \delta$ calculated as $0.0788 \mathrm{~mm}$ ).

\subsubsection{Specimens of Oh et al. [29]}

The sequence of failure modes among plate yielding (PY), plate debonding/separation at end (PS) and at mid (PS mid) and peeling/diagonal tension failures (DT) have also been successfully captured for all 12 beams as summed up in Table 2 and Fig. 5 (Exception: Shear compression failure cannot be captured by the current model for beam S43S4). The under-reinforced beam, for example beam S23, S33 and beams with larger shear span such as S43S1 and S43S2, fail in ductile flexural manner with comparatively larger crack widths (see Table 1). It is noted that for the beams failing prematurely, the theoretical values for average crack width, average crack height, depth of neutral axis and capacity of section cannot be compared with those of FE model or tests' results. It is because the theoretical values are computed at full capacity of section failing in flexure.

Fig. 5(a) and (b) respectively indicate the effect of plate thickness and adhesive thickness on overall behaviour. Increase in either thicknesses result into stiffer beam, while this is comparatively less with adhesive thickness. This may be due to that adhesive hardly contributes to structural stiffness and is only altering lever arm of the section. As recorded in Table 1 that with the increase in total reinforcement, the average crack height and

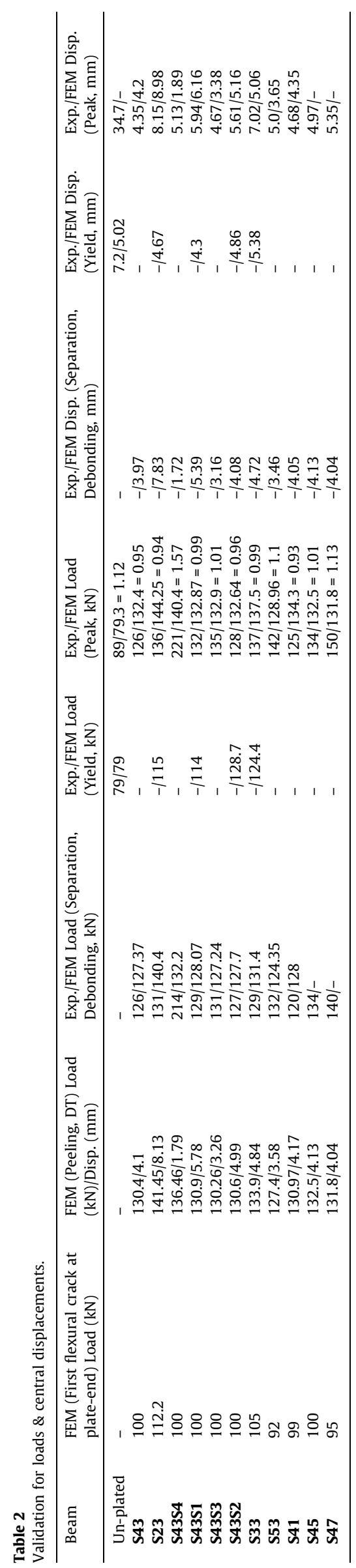




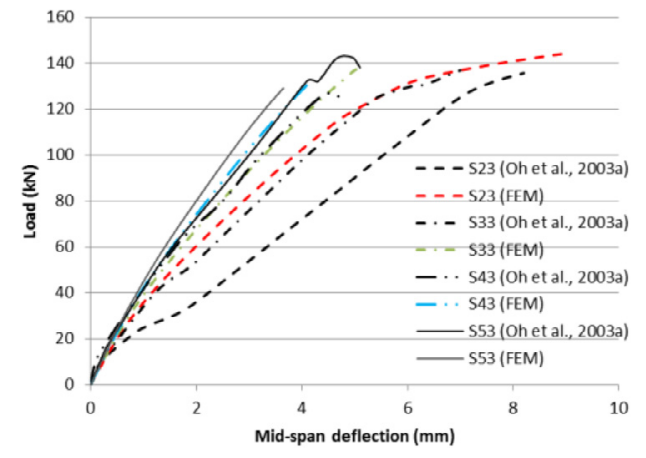

(a) Beams with varying plate thickness

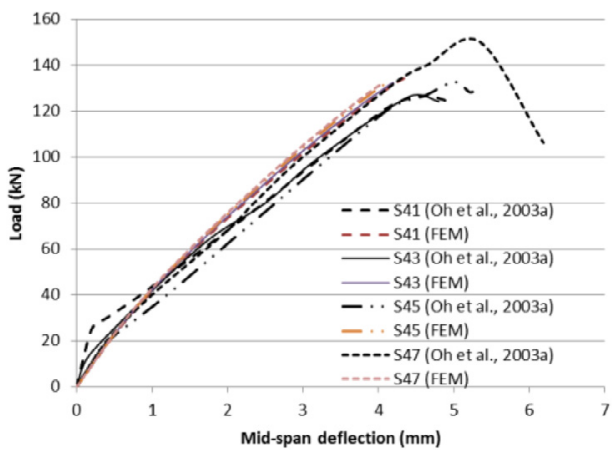

(b) Beams with varying adhesive thickness

Fig. 5. Load verses displacement validations.

average crack width consistently decrease and the depth of neutral axis increases.

Beam S23 indicates a relatively large difference in such behaviour at the middle of analysis, while this gap is reduced at the end of analysis with the yielding of plate. Beam S43 shows a slight deviation in the beginning and beam S41 shows a relatively large deviation; however as the load progressed this difference is reduced. At the end of analysis the test-to-numerical ratio at peak load is attained to be 1.12, 0.95, 0.94, 1.57, 0.99, 1.01, 0.96, 0.99, $1.1,0.93,1.01$ and 1.13 for beams Control, S43, S23, S43S4, S43S1, S43S3, S43S2, S33, S53, S41, S45 and S47 respectively (see Table 2). S41 first fails in debonding at plate end and followed by peeling.

The effect of $a / d$ ratio are also validated and verified at ultimate capacities Fig. 6. In all cases the results overlap except for the very low shear-span to depth ratio of 1.36 .

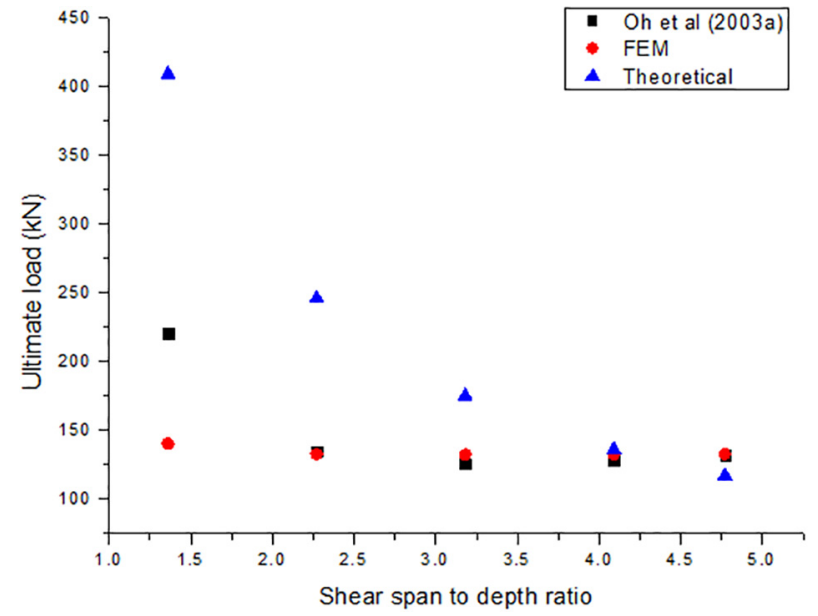

Fig. 6. Comparison of ultimate capacities.
Oh et al. [29] noted that the diagonal cracks occurred with the separation of steel plates, the crack propagated further diagonally. FE investigation further indicated that this behaviour is due to high stress concentrations at plate end that created flexural crack before plate started to debond along the interface (refer Fig. 7). The vertical axes indicate cohesive percentage damage SDEG and flexural strain E11End. The meaning of the abbreviations used to identify modes of failure at two critical locations in Fig. 8 are summed up in Table 3. The loads of appearance of first flexural cracks are noted in Table 2. The flexural crack initiated before debonding and grew comparatively rapidly; however, beam first fails in former mode of failure (debonding at $132.2 \mathrm{kN}$ ) as in experiments, after which a

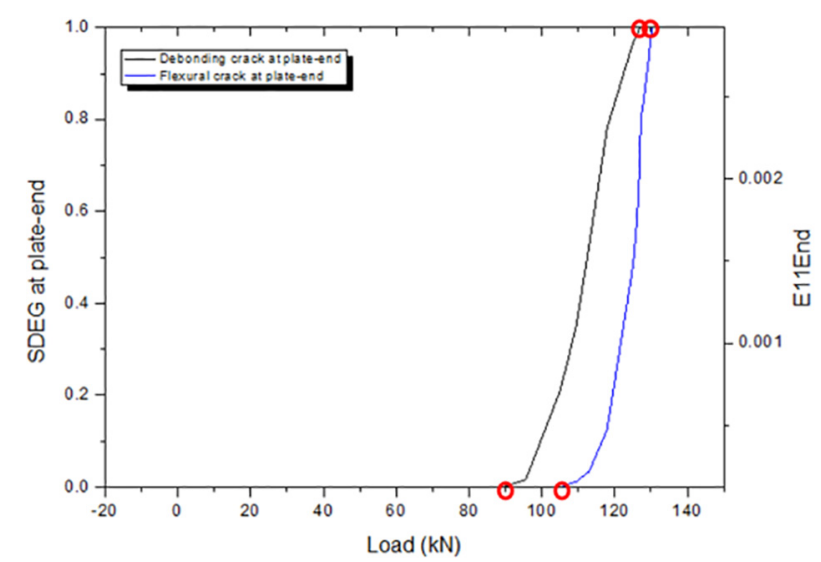

Fig. 7. Appearance and formation of debonding and flexural cracks at plate end for beam S43S3.

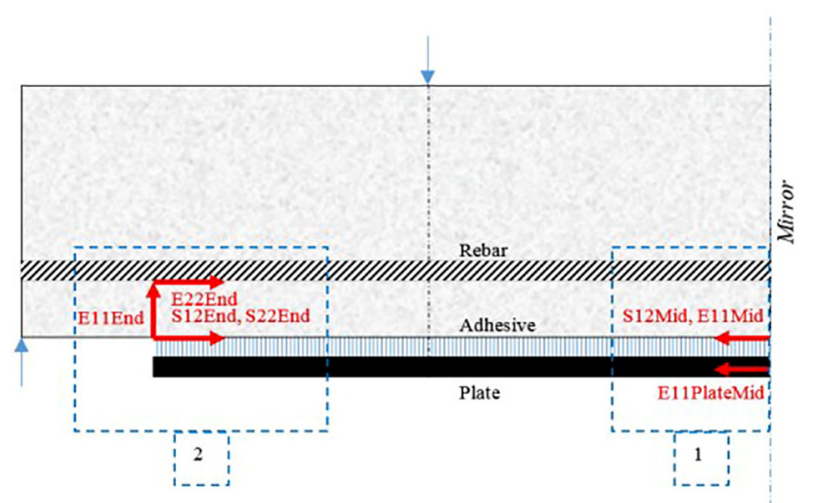

Fig. 8. Crack representaions at critical locations for modes of failure: 1) Yielding of steel and Debonding, 2) Peeling and Debonding.

Table 3

Abbreviations for failure modes.

\begin{tabular}{ll}
\hline Abbreviation & Explanation \\
\hline E11End & Flexural (tensile) strain on covercrete at plate end \\
E22End & Tensile strain along the rebar-covercrete interface \\
E11Mid & Flexural (tensile) strain on covercrete at mid span \\
E11PlateMid & $\begin{array}{l}\text { Flexural (tensile) strain on plate at mid span } \\
\text { S12End }\end{array}$ \\
& $\begin{array}{l}\text { Shear stress at the concrete-adhesive surface at plate ends } \\
\text { (Transverse direction) }\end{array}$ \\
S22End & $\begin{array}{l}\text { Normal stress at the concrete-adhesive surface at plate ends } \\
\text { (Normal direction) }\end{array}$ \\
S12Mid & $\begin{array}{l}\text { Longitudinal shear stress at the concrete-adhesive interface at } \\
\text { mid span (Transverse direction) }\end{array}$ \\
E11Cover & $\begin{array}{l}\text { Distribution of flexural strains along the adhesive-covercrete } \\
\text { interface }\end{array}$ \\
&
\end{tabular}


complete flexural crack forms (peeling at $136.46 \mathrm{kN}$ ) to propagate further diagonally upwards.

For example, to assess the comparative behaviour of crack types, the development of tractions and strains at critical location of beam S41 are plotted in Fig. 9.

The debonding crack and flexural crack appear at plate end at $93 \mathrm{kN}$ and $100 \mathrm{kN}$ respectively. After this, the cohesive stresses at plate end decrease gradually. This may be due to opening or closing of cohesive crack. The investigation of cohesive damage indicates a debonding crack (also see Fig. 10). At a load of $110 \mathrm{kN}$, there is further accumulation of stresses at plate end resulting into increase in the development rate of flexural strain (E11End) and interfacial stresses; the flexural crack propagates to initiate at rebar-covercrete interface (E22End) at $124 \mathrm{kN}$. The debonding occurs at $128 \mathrm{kN}$ (first mode of failure). After this, the ultimate capacity of beam is seen in peeling at $134 \mathrm{kN}$ (complete crack, second mode of failure). The relative comparison of tensile strains in covercrete at plate end (E11End) and along the rebar-covercrete interface (E22End) with the applied load confirms the peeling failure originating from plate end and propagating along the rebarcovercrete interface. It indicates that the peeling failure is an ultimate consequence of flexural failure at plate end. However, more investigation is needed to study the possible propagation of cracks along the rebars.

\subsection{Effect of parameters}

The failure of a plated beam is not solely governed by its failure in flexure, rather this also include premature cracks. This indicates that the overall brittleness of beam (rapidness of failure) is directly

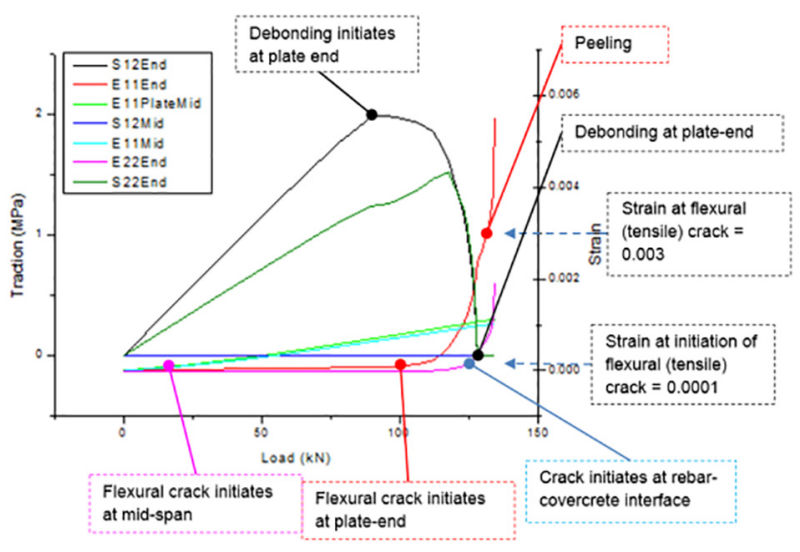

Fig. 9. Behaviour of control beam at critical regions.

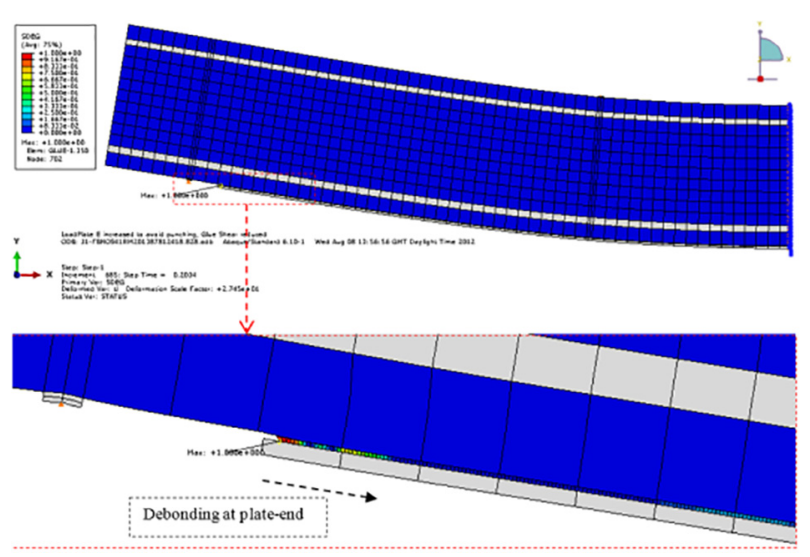

Fig. 10. Location and propagation of debonding failure for control beam. dependent on the behaviour or brittleness of failure mode(s). Therefore, in addition to focussing on the relative response of critical sections, the relative effect of parameters (primary, secondary or local) on modes of failure are also analysed and discussed based on achievable percentage of the ultimate carrying capacity of the beam at the appearance of first crack $F_{1} / F_{u} \times 100 \%$, which is brittleness of failure mode(s) [39]. In Fig. 11, the filled dots indicate the first mode of complete failures; clearly, this is not necessarily be same as the first mode of crack initiation. A higher ratio will indicate a relatively brittle or catastrophic nature of failure.

\subsubsection{Fracture energy for covercrete $\left(\boldsymbol{G}_{\boldsymbol{f c} \_ \text {covercrete }}\right)$}

The behaviour of the beams remained identical until the formation of flexural crack at the load of $21 \mathrm{kN}$ at mid-span and $100 \mathrm{kN}$ at plate-end. As this crack is formed at a load higher than that required for debonding cracks to form, the load at the formation of debonding cracks at plate end remained unaffected at $93 \mathrm{kN}$. The increase in fracture energy of the cover seems to have two main effects: the first is to increase the ultimate load capacity of the beam to certain extent (maximum reached is $139 \mathrm{kN}$ for this beam), and the second is to influence the modes of failure mainly peeling and debonding at plate end. Increasing fracture energy beyond $0.1 \mathrm{~N} / \mathrm{mm}$ has no impact to increase ultimate capacity any further. However, for reduced value of crack energy of $0.03 \mathrm{~N} / \mathrm{mm}$, the ultimate capacity was reduced by $6.7 \%$.

The increased fracture energy of covercrete provided a means to redistribute debonding stresses, now resulting into peeling as first mode of failure instead of debonding. Increased fracture energy predominantly reduced rate of formation of flexural cracks (see Fig. 12), and relatively smeared distribution of flexural strains (Fig. 13), but it couldn't prevent localisation of stresses at plate end which is due to geometrical discontinuities.

In terms of brittleness of failure modes, for crack energy of $0.03 \mathrm{~N} / \mathrm{mm}, 0.042 \mathrm{~N} / \mathrm{mm}$ (control), $0.1 \mathrm{~N} / \mathrm{mm}, 0.3 \mathrm{~N} / \mathrm{mm}$ and 1 $\mathrm{N} / \mathrm{mm}$, the percentage of ultimate capacity achieved through the formation of interfacial crack are $74.4 \%, 69.4 \%$ (control) $66.6 \%$, $67.4 \%$ and $67.4 \%$ and though the appearance of flexural crack are $80 \%, 74.6 \%$ (control), $71.6 \%, 72.5 \%$ and $72.5 \%$ respectively.

\subsubsection{Thickness of adhesive layer $\boldsymbol{t}_{\boldsymbol{g}}$}

Variation of adhesive thickness seems to influence mainly two modes of premature failure as debonding at plate end and peeling. The load of appearance of debonding crack at plate end increased slightly with the increase in adhesive thickness, later for higher thicknesses of $5 \mathrm{~mm}$ and $7 \mathrm{~mm}$ the interfacial crack at plate end did not form. The increase in thickness slightly increased the brittleness of the beam. It can be seen from Fig. 11(a), if the adhesive thickness is increased to $7 \mathrm{~mm}$, the flexural crack at plate end appeared at $74 \%$ of the ultimate capacity compared to $69 \%$ for control case with debonding crack.

\subsubsection{Tensile strength for concrete $\boldsymbol{f}_{\boldsymbol{t c}}$}

With the relative increase in $f_{t c}$, the overall behaviour of beam becomes stiffer, and the load of appearance of interfacial crack and flexural crack at plate end increased significantly. The behaviour of crack (at E11End) with $f_{\text {tc }}$ of $7 \%, 10 \%, 25 \%$ and $50 \% f_{c}^{\prime}$, overlapped until the appearance of first flexural crack. The corresponding load of appearance of this crack are $14 \mathrm{kN}, 21 \mathrm{kN}$, $50 \mathrm{kN}$ and $99 \mathrm{kN}$. Thereafter, the available fracture energy effected the brittleness of crack and generated convergence issues with the numerical model for high strengths of $25 \%$ and $50 \% f_{c}^{\prime}$ with respectively remaining with only 5 and 1.2 times of elastic strain after crack initiation. A flexural crack at plate end appeared at the load of $70 \mathrm{kN}$ for the beam with $7 \% f_{c}^{\prime}$ as compared to control case of $100 \mathrm{kN}$. Due to early formation of flexural crack, the debonding 


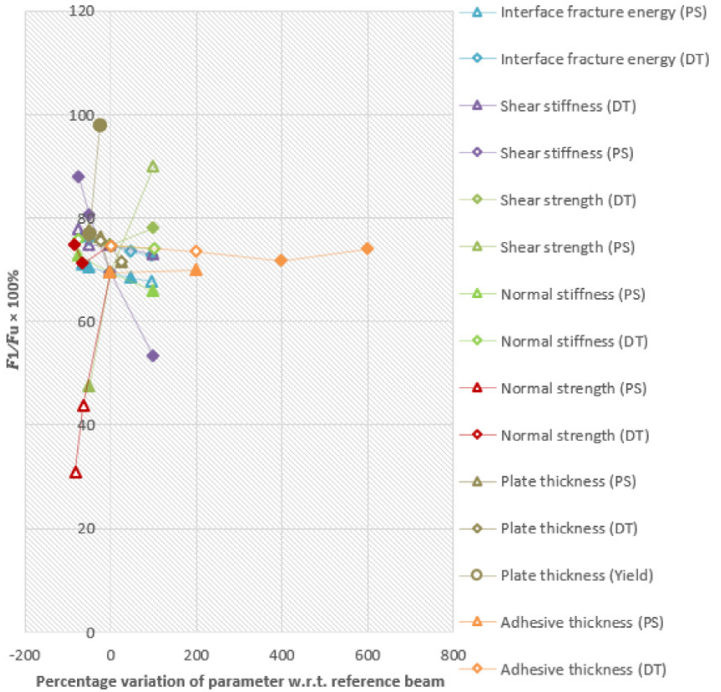

(a) Primary parameters

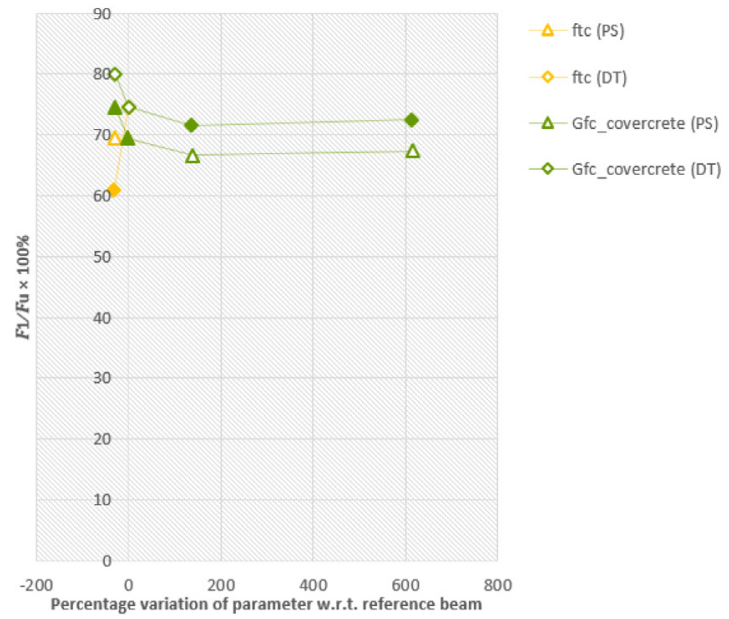

(b) Secondary parameters

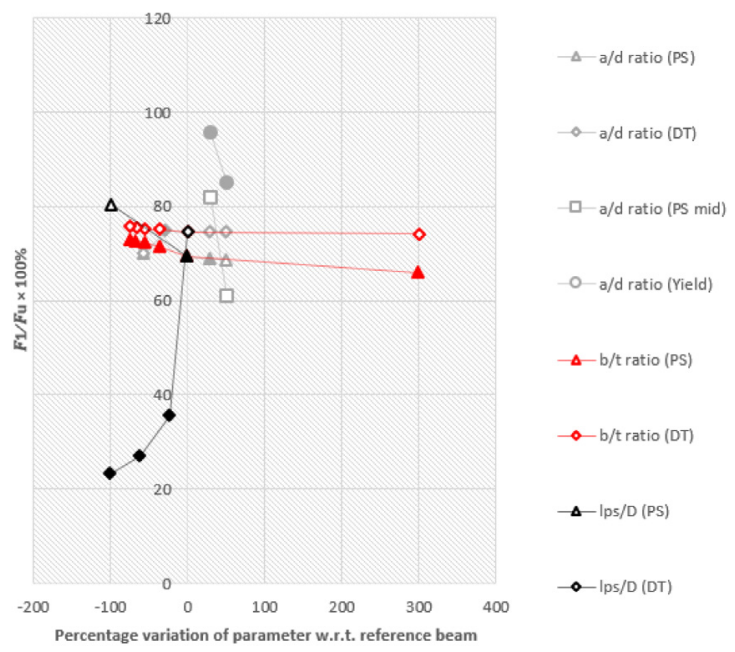

(c) Local parameters

Fig. 11. Brittleness of failure modes for the choice of parameters.

crack initiated at plate end at a load of $80 \mathrm{kN}$ compared to control case at $93 \mathrm{kN}$, and did not debond with maximum degradation of

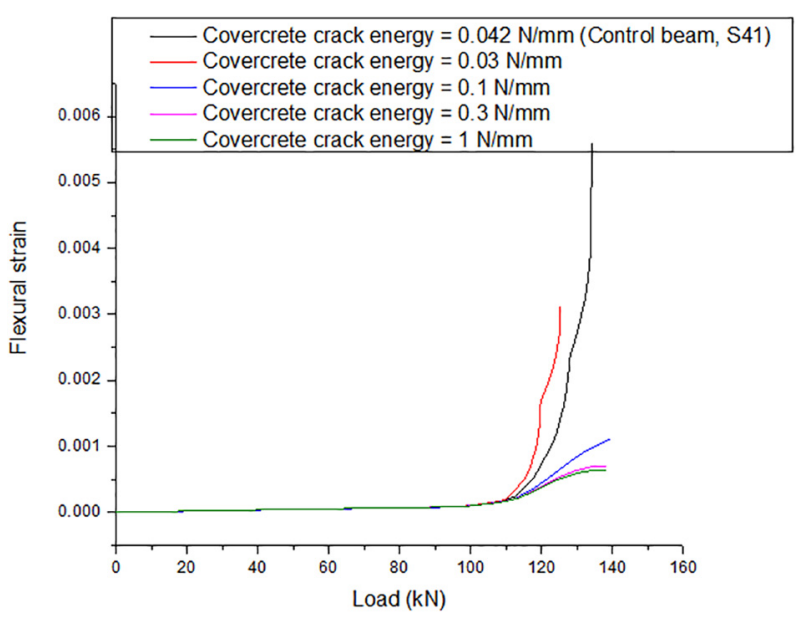

Fig. 12. Effect of $G_{f c_{-} \text {covercrete }}$. the development of E11End.

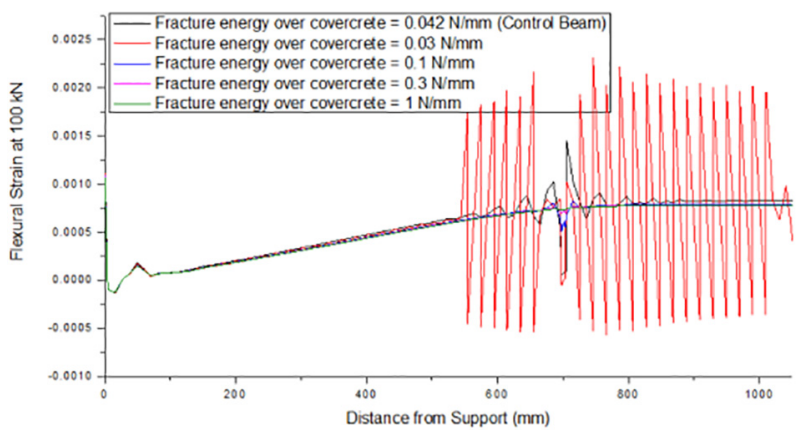

Fig. 13. Effect of $G_{f c}$ covercrete. the distribution of flexural strains over adhesivecovercrete interface.

cohesive element recorded to be at $60 \%$. While a control beam failed in debonding at plate end at a load of $128 \mathrm{kN}$, a beam with only $3 \%$ reduction in the available tensile strength failed in peeling at a load of $115 \mathrm{kN}$. Analysis also indicated that increase in tensile strength can avoid a highly catastrophic mode of failure as peeling by avoiding an early formation of flexural crack. For lower value, the premature crack appeared at around 61\% (flexural crack at plate end) of its ultimate capacity as compared to 69\% (interfacial crack at plate end) for control case.

\subsubsection{Plate width to thickness ratio $\boldsymbol{b}_{\boldsymbol{p}} / \boldsymbol{t}_{\boldsymbol{p}}$}

While maintaining the cross sectional area of plate, the higher $b_{p} / t_{p}$ ratios resulted in the appearance of debonding cracks at slightly lower load and ultimate capacity at slightly higher load. Whereas, the theoretical model of [16] indicated a substantial increase in peeling capacity with increase in $b_{p} / t_{p}$ ratio. In contradiction to Macdonald [30], $b_{p} / t_{p}$ ratio did not affect the mode of failure. The fact that such variations in literature can be attributed towards changing geometry of the beam and the cross sectional area of plate, is also supported by Swammy's discuusion on Hussain ([2]. The observations are in agreement with [40] for $b_{p} / t_{p}$ of less than $\mathbf{4 0}$ that the plate fails at plate end and not in pure flexure. The ultimate capacity remained largely unaffected with the deviation of only $0.75 \%$ and $-1.5 \%$ for change in ratio by $300 \%$ and $-75 \%$ (for the range of 150 to 9.4 respectively). Judging on the brittleness of debonding, the load of appearance of interfacial crack at plate end is relatively reduced for ratio of $-36 \%, 0 \%$ and $300 \%$.

\subsubsection{Plate thickness $\left(\boldsymbol{t}_{\boldsymbol{p}}\right)$}

While changing the overall amount of reinforcement is expected to directly affect the overall response of beam, the effects 
are specifically noted on cracks. With the increase in plate thickness, relatively low flexural strains are noticed at mid-span as these tend to concentrated at plate end. Unlike for case with fixed cross sectional area of plate, yielding of plate is observed for $2 \mathrm{~mm}$ $\left(b_{p} / t_{p}=75\right)$ and $3 \mathrm{~mm}\left(b_{p} / t_{p}=50\right)$ plate at respectively $113 \mathrm{kN}$ (due strain localisation as identified by [41]) and $137 \mathrm{kN}$. A further increase in strain rate is also noted at $134.9 \mathrm{kN}$ due to yielding of tensile $b_{p} / t_{p}$ rebars for beam with $2 \mathrm{~mm}$ plate (refer Fig. 14), this was followed by debonding and peeling failures. For $3 \mathrm{~mm}$ plate case, the effect of yielding is not captured through a sudden increase in the rate of development of longitudinal strains. It may be due to the fact that debonding at plate end occurred at $133 \mathrm{kN}$ before plate yielded; and the beam observed peeling at $140 \mathrm{kN}$ (catastrophic failure within a short period). The conclusions are in agreement with the statistical observations of [42] that the use of a thicker plate will reduce the ultimate plate peeling capacity of the beam. However case sensitive, the percentage changes in numerical capacities w.r.t. theoretical capacities are plotted in Fig. 15; expect for $2 \mathrm{~mm}$ plate that profoundly failed in flexure at first mode of failure. It is noted that at flexure failure, the FEM capacities can also be higher than the corresponding theoretical capacities due to the fact that concrete in compression has not fully yielded; this further affirms that the load-displacement plot is not a horizontal plateau after the formation of plastic hinge in real scenario. Such behaviours indicate that, although, a theoret-

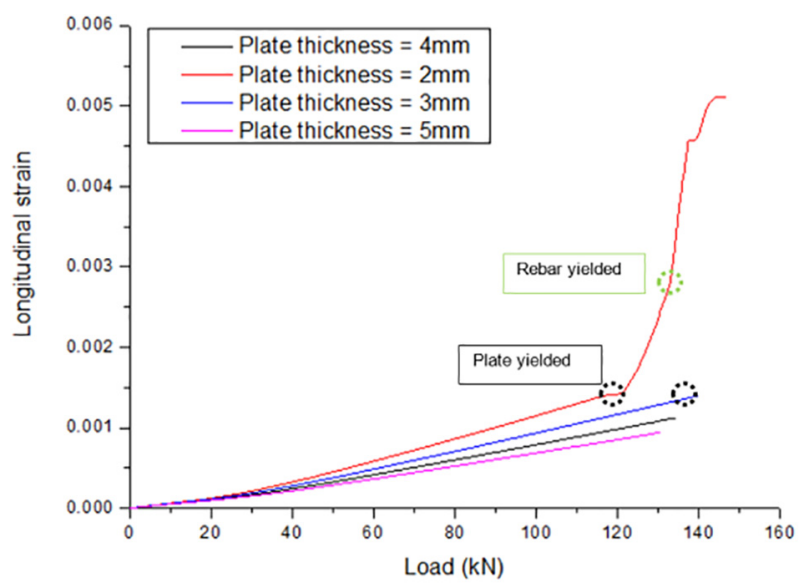

Fig. 14. Development of longitudinal strain (E11PlateMid) at plate mid with $t_{p}$.

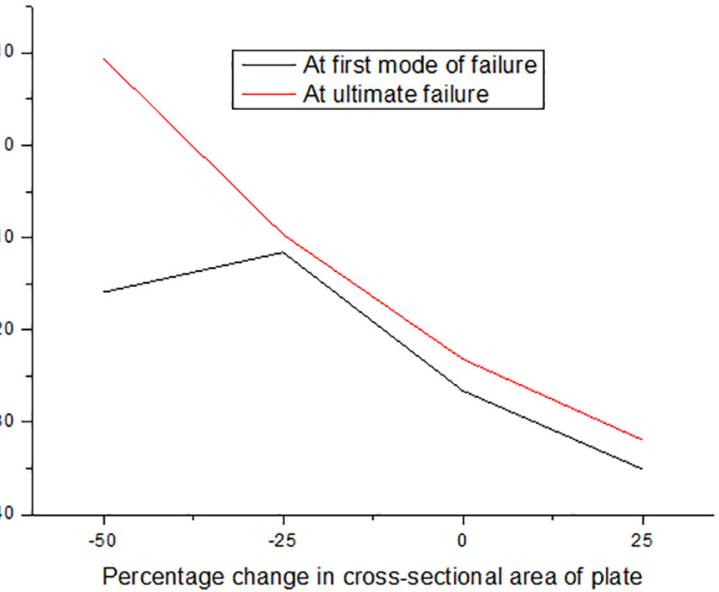

Fig. 15. Variation in FEM capacities w.r.t theoretical capacities with $t_{p}$. ical capacity in flexure can still be achieved for a given set of parameter(s); however, premature failures are still unavoidable. Therefore, it becomes increasingly important to compare brittleness of failure modes under different parameters. For plate thickness of $2 \mathrm{~mm}, 3 \mathrm{~mm}$, and $5 \mathrm{~mm}$, the ultimate capacities changed by $9.7 \%$, $4.5 \%$ and $-3 \%$ relative to the control beam.

\subsubsection{Plate length in shear-span to sectional-depth ratio $\boldsymbol{I}_{p s} / \boldsymbol{D}$}

Theoretically, full capacity should be achieved with the plates covering pure flexural span or larger, unless rebars are yielded beyond the point covered by plate. However, it is noticed that the presence of premature failure(s) has dominated the behaviour of beam in terms of load deflection behaviour (Fig. 16), capacity and mode of failure. In addition to reduced stiffness with shorter plate, a relatively early formation of premature $\operatorname{crack}(\mathrm{s})$ in the form of peeling has softened the load-deflection behaviour. For smaller plate, the flexural strains at plate end (Fig. 17) increased rapidly relative to interfacial stresses. The increase in the load of appearance of first $\operatorname{crack}(\mathrm{s})$, increase in ultimate capacity, increased ductility and the reduced rate of stress and strain development at critical regions with the use of longer plate clearly pushes a need to extend the flexural plate as close to support as possible.

If $l_{p s} / D$ ratio is reduced to 2,1 and 0 , the flexural crack at plate end appeared relatively earlier at $0.31 \%, 14 \%$ and $9.5 \%$ of the ultimate capacity for the corresponding beams. The corresponding

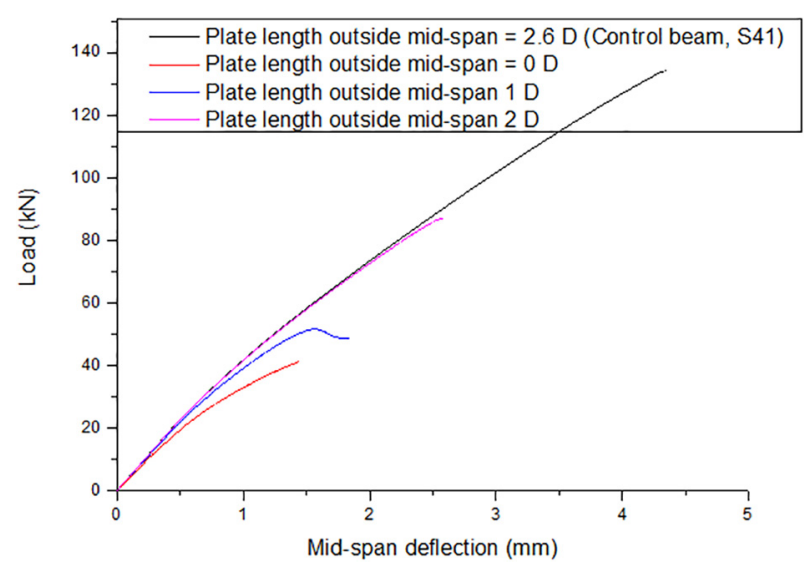

Fig. 16. Load vs. deflection behaviour with $1 \_\{p s\} / D$ ratio.

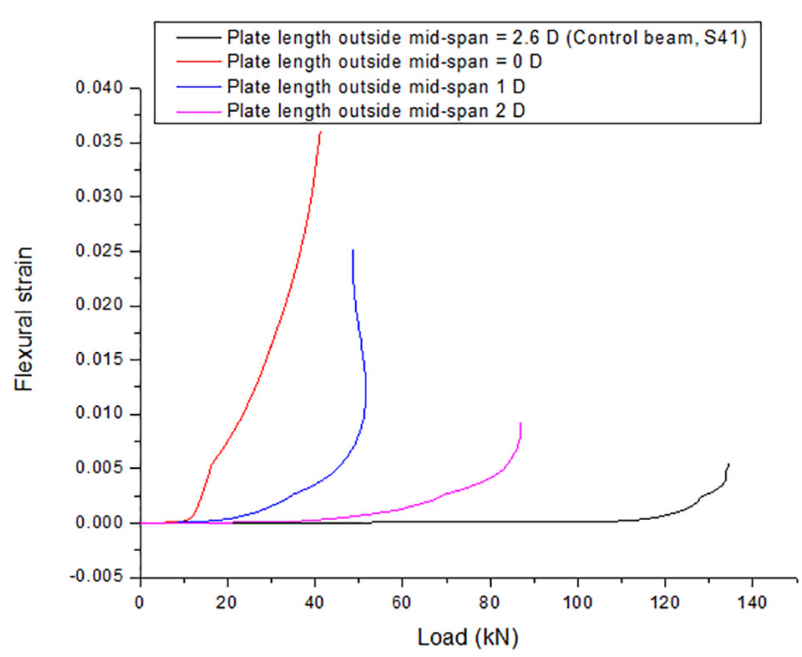

Fig. 17. Development of flexural strain (E11End) at plate end covercrete with $1 \_\{\mathrm{ps}\} / \mathrm{D}$ ratio. 
ultimate capacities are noted to significantly decrease by $35 \%$, $61.4 \%$ and $69.4 \%$ relative to control beam.

\subsubsection{Shear span to depth ratio $\boldsymbol{a} / \boldsymbol{d}$}

The effect of shear span to depth ratio is plotted against the brittleness of mode(s) of failure in Fig. 11(c). With varying ratio, the beams observed mainly four modes of premature failure as debonding at plate end, peeling, debonding at plate mid and plate yielding.

Changing $a / d$ ratio did not affect the brittleness of the beam until relatively high $a / d$ ratio of 4.77 , at which four-point bending problem converged to a three-point bending problem that witnessed the appearance of debonding crack originating from midspan at relatively early stage of loading, later failing with yielding of plate. Interfacial crack at plate end determined the brittleness of the beam for all cases, except for low $a / d$ ratio of 1.36 where a flexural crack appeared simultaneously at plate end. The percentage load of appearance of debonding and flexural crack at plate end remained unaffected at around $69 \%$ and $74 \%$ respectively except for the case with low $a / d$ ratio of 1.36 where flexural crack appeared at $70 \%$. For larger $a / d$ ratios of 4.09 and 4.77 , the percentage load of appearance of interfacial crack at mid-span and yielding is largely affected. Such load percentages are found to be $82 \%$ and $61 \%$ for interfacial crack at mid-span, and $96 \%$ and $85 \%$ for plate yielding with $a / d$ ratio of 4.09 and 4.77 respectively. The ultimate capacity remained largely unaffected except for very low $a / d$ ratio of 1.36 (that is, $6.7 \%$ increase compared to control case). For $a / d$ ratio of 4.09 , first modes of complete failure are noted to be debonding at plate end and yielding of plate at mid-span together. Noteworthy is the fact that, the capacity at first mode of failure for $a / d$ ratio of 4.09 remained same as for control beam failing in debonding at plate end at $128 \mathrm{kN}$. This capacity is reduced at $114 \mathrm{kN}$ for increased $a / d$ ratio of 4.77 . In Fig. 18, higher flexural strains are observed within flexural span for sections with higher $a / d$ ratios extracted at same load of $100 \mathrm{kN}$. A load of $100 \mathrm{kN}$ is selected for the purpose because at this point the beams are at reasonable stage to represent the good accuracy for comparison. At this stage, cracks are already propagating, yet no complete mode of failure was observed. Such behaviour indicates that high values of $a / d$ ratio would reduce the possibility of premature failure to be first complete mode of failure but it may not however improve the capacity of the beam. In addition, the analysis indicates that the $a / d$ ratio of around $\mathbf{4 . 0 9}$ is required to achieve maximum capacity of plated-beam in flexure.

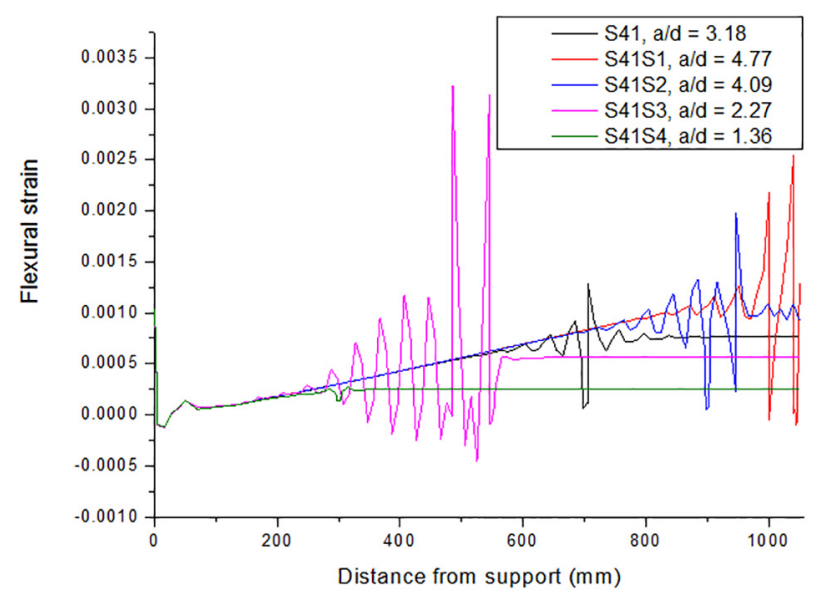

Fig. 18. Flexural strain distribution along the adhesive-covercrete interface with $a / d$. tio at $100 \mathrm{kN}$.

\subsubsection{Interface or adhesive material properties}

The effect of adhesive material properties, such as normal stiffness $K_{g \sigma}$ and transverse stiffness $K_{g \tau}$, normal strength $t_{n}$ and transverse strength $t_{s}$, and interface fracture energy $G_{f c \_ \text {interface }}$, are also studied using cohesive zone model by [39]. As they primarily focussed on debonding, therefore the effect of such parameters is briefly extended here towards studying other types of failures as well (including peeling). This establishes an overall picture of the relatively influence of modes of failure on the brittleness of beam.

\section{Conclusion}

Findings are outlined in terms of qualitative and quantitative observations as follows:

\subsection{Qualitative conclusions}

Based on the analysis that signifies the importance of each parameter in terms of their influence on formation and behaviour of modes of failures, crack distribution and ultimate capacity, the parameters are grouped and arranged in sequence of their reducing qualitative importance into four groups as below:

i. Plate length in shear-span to sectional-depth ratio; tensile strength for concrete; shear span-to-depth ratio; plate thickness

ii. Shear strength of interface; shear stiffness of interface; interface fracture energy; fracture energy of covercrete (in tension)

iii. Normal strength of interface; normal stiffness of interface

iv. Adhesive thickness; plate width-to-thickness ratio.

However, to establish clear picture on the relative/individual influence(s) of each parameter on the overall performance of the beam, the conclusions based on the quantitative observations are drawn next.

\subsection{Quantitative conclusions}

The general observations of critical importance within a practical range of the parameters are noted as follows.

- $t_{\mathrm{g}}$ : The range of $] 3,5[\mathrm{~mm}$, that is less than or equal to $3 \mathrm{~mm}$ and more than or equal to $5 \mathrm{~mm}$, achieves peeling failure and debonding failure respectively.

- $K_{\mathrm{g} \tau}>1 \mathrm{GPa} / \mathrm{mm}$ :

o Has relatively negligible effect on E11Cover, E11Mid, S12Mid

o A relatively softer adhesive leads to interfacial cracks at mid-span by allowing for larger opening of flexural cracks in its surroundings.

- $G_{f \_\_c o v e r c r e t e}>0.1 \mathrm{~N} / \mathrm{mm}$ :

o Has negligible effect on the ultimate capacity, strain distribution and failure brittleness.

o Avoids peeling

0 Increases the capacity in debonding to limited extent - $a / d \approx 4.09$ achieves a maximum capacity in flexure

The critical influence(s) of each parameter are drawn based on their relative quantitative influence(s) on the beam in terms of Positive contribution criterion. Positive contribution is seen as improving both the ultimate capacity of beam and $\operatorname{crack}(\mathrm{s})$ brittleness.

i. $G_{f c \_c o v e r c r e t e}$ : Inceresed value has a positive contribution until $0.1 \mathrm{~N} / \mathrm{mm}$, after this value no change is observed 
ii. $b_{p} / t_{p}$ : A very high ratio of 150 (for $2 \mathrm{~mm}$ thick plate) gives positive contribution towards debonding

iii. $a / d$ : For very low ratio of 1.36 , the ultimate capacity for the beam is improved, thereby reducing the peeling-brittleness

iv. $t_{g}$ : Increased value up to $5 \mathrm{~mm}$ improves peeling-brittleness and ultimate capacity, than reduces afterwards

v. $G_{f c \_i n t e r f a c e}$ increasing gives positive contribution towards ultimate capacity

vi. $K_{g \tau}$ and $K_{g \tau}$ : increasing the values give positive contribution towards debonding

vii. $t_{s}$ and $t_{n}$ : Lower values improve crack-brittleness. Relatively lower values significantly reduce ultimate capacity.

\section{Financial support}

Research Studentship, Loughborough University, UK.

\section{Acknowledgements}

The present work is part of corresponding author's PhD thesis, funded ${ }^{\dagger}$ by the School of Civil and Building Engineering and submitted under the supervision of Dr. Jamal El-Rimawi and, Prof. Vadim V. Silberschmidt at Loughborough University (UK).

\section{Appendix A}

\section{Theoretical properties of flexural crack}

The size of element affects the fracture energy as it is based on element width. It is represented in Fig. A1.

From Fig. A1, the average crack width is:

$\delta=\epsilon b$

Fig. A2(a) corresponds to the material behaviour in Fig. A2(b). The value of $a^{*}$ can be determined by assuming an arbitrary notch, that is $\delta>\delta^{f}$. Noteworthy is that at concrete-adhesive interface, $\delta$ will also be common to CZM.

Since also using Fig. A.3 at curvature $k, \frac{y^{\prime}}{\epsilon_{b}}=\frac{y}{\epsilon_{0}}=\frac{1}{k}$, gives:

$h^{\prime}=\frac{\delta^{\prime}}{b} \frac{y^{\prime}}{\epsilon_{b}}$

The average height of notch is given as $\mathrm{d}^{\prime}$ :

$d^{\prime}=c-a^{*}=\frac{\Delta \delta}{b} \frac{1}{k}$

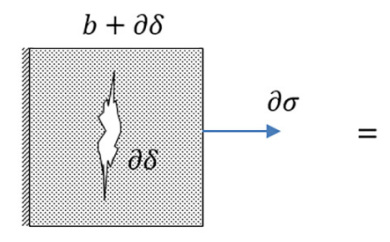

Discrete

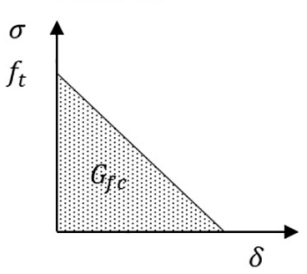

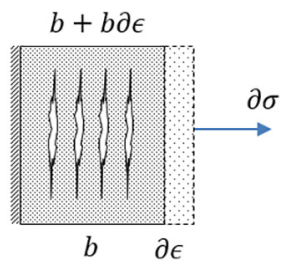

Smeared

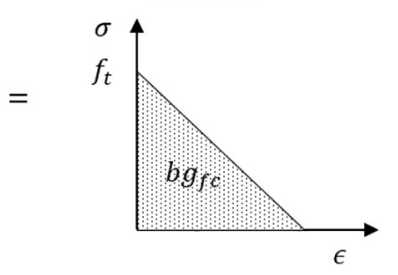

Fig. A1. Discrete and smeared representation of $\operatorname{crack}(\mathrm{s})$. where, $\quad \Delta \delta=\delta-\delta^{f}=($ Tensile strain at bottom fibre - Plastic failure strain for tensile concrete) $\times$ Element characteristic width.

From Fig. A2(a), the crack opening in terms of crack angle can be obtained as:

$\delta=2 d^{\prime} \tan \left(\frac{\theta}{2}\right)+\delta^{f}$

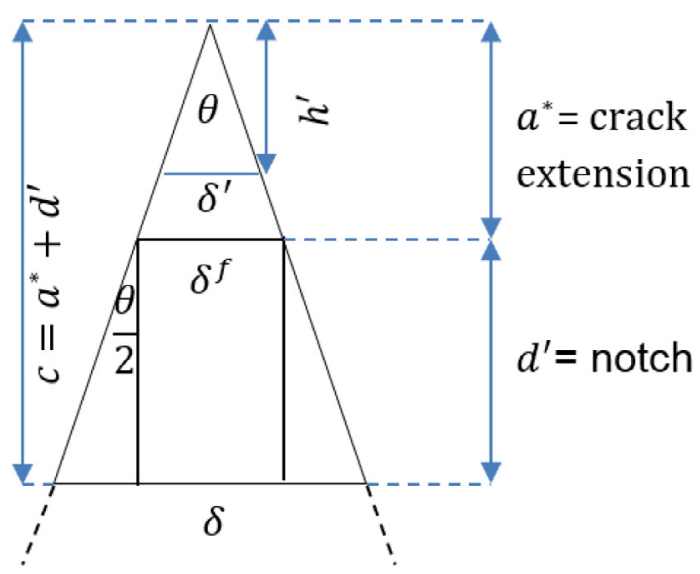

(a)

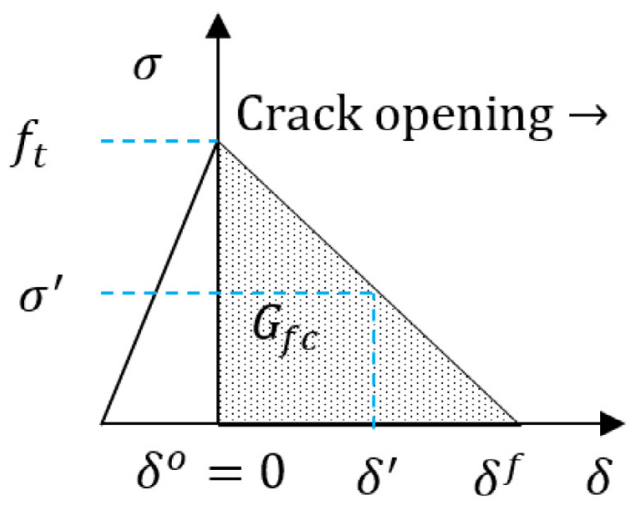

(b)

Fig. A2. Theoretical crack model (a) Representation for arbitrary notch, (b) Bilinear opening of crack mouth Fig. A3. Representation of bisection rule.

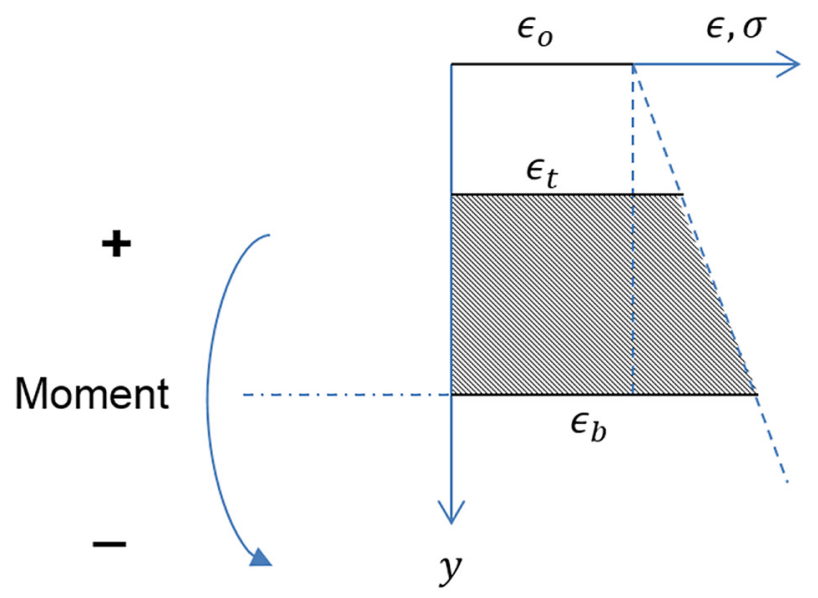

Fig. A3. Representation of bisection rule. 
Since,

$\tan \left(\frac{\theta}{2}\right)=\frac{\delta^{f} / 2}{a^{*}}$

This gives,

$\delta=\left(\frac{d^{\prime}}{a^{*}}+1\right) \delta^{f}$

Or,

$a^{*}=\frac{\delta^{f}}{\delta} c$

After the value of $a^{*}$ is calculated, the height of notch can be found by:

$d^{\prime}=c-a^{*}=\left(1-\frac{\delta^{f}}{\delta}\right) c$

Therefore, three cases are possible:

Case I: $\delta<\delta^{f}$

$d^{\prime}$ is negative. This indicates notch does not form.

$G_{f c}^{\prime}=0.5\left(f_{t}+\sigma^{\prime}\right) \delta^{\prime} b$

where, $\sigma=f(\delta)$

Case II: $\delta=\delta^{f}, \lim _{\delta^{\prime} \rightarrow \delta^{f}} f(\delta)=0$

$d^{\prime}$ is zero.

$\lim _{\delta^{\prime} \rightarrow \delta^{f}} G_{f c}^{\prime}(\delta)=G_{f c}=0.5 f_{t} \delta^{f} b$

Case III: $\delta>\delta^{f}, \lim _{\delta^{f} \rightarrow \delta} f(\delta)=0$

$d^{\prime}$ is positive. This indicates that notch forms.

$\lim _{\delta^{f} \rightarrow \delta} G_{f c}^{\prime}(\delta)=G_{f c}^{\text {gross }}=0.5 f_{t} \delta b$

Or, the crack energy can also be represented in terms of crack length using Eq. (8):

$\delta=\frac{c}{a^{*}} \delta^{f}$

$G_{f c}^{\text {gross }}=0.5 f_{t}\left(\frac{c}{a^{*}} \delta^{f}\right) b$

Therefore, the fracture energy liberated to form a notch can be calculated as:

$G_{f c}^{\text {notch }}=G_{f c}^{\text {gross }}-G_{f c}=0.5 f_{t} \Delta \delta b$

\section{References}

[1] Hamoush SA, Ahmad SH. Static strength tests of steel plate strengthened concrete beams. Mater Struct 1990;23(2):116-25.

[2] Hussain $\mathrm{M}$ et al. Flexural behavior of precracked reinforced concrete beams strengthened externally by steel plates. ACI Struct J 1995:92(1):14-22.

[3] Oehlers DJ. Reinforced concrete beams with plates glued to their soffits. Struct Eng 1992;118(8):2023-38.

[4] Oehlers DJ, Mohamed Ali MS, Luo W. Upgrading continuous reinforced concrete beams by gluing steel plates to their tension faces. I Struct Eng $1998 ; 124(3): 224-32$.

[5] Swamy RN, Jones R, Bloxham JW. Structural behavior of reinforced concrete beams strengthened by epoxy-bonded steel plates. Struct Eng 1987;65A (2):59-68.

[6] Swamy RN, Jones R, Charif A. The effect of external plate reinforcement on the strengthening of structurally damaged RC beams. Struct Eng 1989;67 (3):45-56.

[7] Khan MA. FE investigation of failure modes at the soffit of a steel plated RC beam, in School of Civil and Building Engineering. Loughborough, Leicestershire, United Kingdom: Loughborough University; 2014.

[8] Oehlers DJ. Development of design rules for retrofitting by adhesive bonding or bolting either FRP or steel plates to RC beams or slabs in bridges and buildings. Compos A Appl Sci Manuf 2001;32(9):1345-55.
[9] Sebastian W. Significance of midspan debonding failure in FRP-plated concrete beams. J Struct Eng 2001;127(7):792-8.

[10] Saadatmanesh, Malek. Design guidelines for flexural strengthening of RC beams with FRP plates. J Compos Construct 1998;2(4):158-64.

[11] Jones R, Swamy RN, Ang TH. Under- and over-reinforced concrete beams with glued steel plates. Int J Cem Compos Lightweight Concrete 1982;4(1):19-32.

[12] Teng JG, Zhang JW, Smith ST. Interfacial stresses in reinforced concrete beams bonded with a soffit plate: a finite element study. Constr Build Mater 2002;16 (1):1-14.

[13] Smith ST, Teng JG. FRP-strengthened RC beams. I: review of debonding strength models. Eng Struct 2002;24(4):385-95.

[14] Smith ST, Teng JG. Shear-bending interaction in debonding failures of FRPplated RC beams. Adv Struct Eng 2003;6(3):183-99.

[15] Coronado CA, Lopez MM. Sensitivity analysis of reinforced concrete beams strengthened with FRP laminates. Cement Concr Compos 2006;28(1):102-14.

[16] Raoof M, El-Rimawi JA, Hassanen MAH. Theoretical and experimental study on externally plated R.C. beams. Eng Struct 2000;22(1):85-101.

[17] Ziraba YN, Baluch MH. Computational model for reinforced concrete beams strengthened by epoxy bonded steel plates. Finite Elem Anal Des 1995;20 (4):253-71.

[18] Swamy RN, Jones R, Charif A. Shear adhesion properties of epoxy resin adhesives. In: Adhesion Between Polymers and Concrete. RILEM; 1986.

[19] Coronado C. Characterization, modeling and size effect of concrete-epoxy interfaces, in Department of Civil and Environmental Engineering. USA: The Pennsylvania State University; 2006.

[20] Jumaat MZ, Alam A. Experimental and analytical investigations on the structural behaviour of steel plate and CFRP laminate flexurally strengthened reinforced concrete beams. J Appl Sci 2008;8:4383-9.

[21] Adhikary BB, Mutsuyoshi H. Numerical simulation of steel-plate strengthened concrete beam by a non-linear finite element method model. Constr Build Mater 2002;16(5):291-301.

[22] Arslan G, Sevuk F, Ekiz I. Steel plate contribution to load-carrying capacity of retrofitted RC beams. Constr Build Mater 2008:22(3):143-53.

[23] Oh B, Cho J, Park D. Failure behavior and separation criterion for strengthened concrete members with steel plates. J Struct Eng 2003;129(9):1191-8.

[24] Abaqus I. Abaqus/CAE user's manual.. Providence, RI, USA: Dassault Systèmes; 2011.

[25] Khan MA, El-Rimawi J, Silberschmidt VV. Numerical representation of multiple premature failures in steel-plated RC beams. Int J Comput Methods 2017;14 (2):1750035.

[26] Azad AK, Mirza MS, Chan P. Fracture energy of weakly reinforced concrete beams. Fatigue Fract Eng Mater Struct 1989;12(1):9-18.

[27] Wittmann FH. Crack formation and fracture energy of normal and high strength concrete. Sadhana 2002:27(4):413-23.

[28] BSI, Structural Use of Concrete. 1985, British Standards Institution: London.

[29] Oh B, Cho J, Park D. Static and fatigue behavior of reinforced concrete beams strengthened with steel plates for flexure. J Struct Eng 2003;129(4):527-35.

[30] Macdonald MD, Calder AJJ. Bonded steel plating for strengthening concrete structures. Int J Adhes Adhes 1982;2(2):119-27.

[31] Jones R, Swamy RN, Charif A. Plate separation and anchorage of reinforced concrete beams strengthened by epoxy-bonded steel plate. Struct Eng 1988;66 (5):85-94.

[32] Sikadur. Technical Product Data Sheet. 2012 [cited 2012 July 7]; Available from: http://www.sikaconstruction.com/.

[33] Schuler H, Mayrhofer C, Thoma K. Spall experiments for the measurement of the tensile strength and fracture energy of concrete at high strain rates. Int J Impact Eng 2006;32(10):1635-50.

[34] Malvar J, Warren G. Fracture energy for three-point bend tests on single-edge notched beams. Port Hueneme, California 93043: Naval Facilities Engineering Command; 1988.

[35] Institute AC. Building code requirements for reinforced concrete. United States of America: American Concrete Institute; 2002.

[36] 30/94, B., Strengthening of concrete highway structures using externally bonded plates, in Departmental Advice Note. 1994, Department of Transport: UK.

[37] Mohamed Ali MS, Oehlers DJ, Park S-M. Comparison between FRP and steel plating of reinforced concrete beams. Compos A Appl Sci Manuf 2001;32 (9):1319-28.

[38] Heathcote PM. Theoretical and experimental study on FRP or steel plated R.C. beams. In: Civil and Building Engineering. Loughborough, Leicestershire, United Kingdom: Loughborough University; 2004.

[39] Khan MA, Silberschmidt VV, El-Rimawi J. Controlled failure warning and mitigation of prematurely failing beam through adhesive. Compos Struct 2017;161:119-31.

[40] Jones R, Swamy RN, Salman FAR. Structural implications of repairing by epoxybonded steel plates. In: Proc. Second Internat. Conference on Structural Faults and Repairs. London: Engineering Technics Press; 1985.

[41] Teng JG, Yao J. Plate end debonding failures of frp - or steel-plated rc beams: a new strength model. In: Proceedings of the international symposium on Bond Behaviour of FRP in Structures (BBFS 2005). International institute for FRP in Construction; 2005.

[42] Raoof M, Hassanen MAH. Peeling failure of reinforced concrete beams with fibre-reinforced plastic or steel plates glued to their soffits. Proc ICE - Struct Build 2000;140(3):291-305. 